\title{
Review of effects of radiation damage on the luminescence emission of minerals, and the example of He-irradiated $\mathrm{CePO}_{4}$
}

\author{
Lutz Nasdala • Dieter Grambole • Katja Ruschel
}

\author{
Lutz Nasdala $(\bowtie) \cdot$ Katja Ruschel \\ Institut für Mineralogie und Kristallographie, Universität Wien, \\ Althanstr. 14, 1090 Wien, Austria \\ e-mail: lutz.nasdala@univie.ac.at \\ Dieter Grambole \\ Institut für Ionenstrahlphysik und Materialforschung, Helmholtz-Zentrum Dresden, \\ P.O. Box 510119, 01314 Dresden, Germany
}

\begin{abstract}
The accumulation of structural damage that is created in minerals upon corpuscular irradiation, has two apparently contrarious effects on their luminescence behaviour. First, irradiation may cause the generation of luminescent defect centres, which typically results in broad-band emissions. Such defect emissions are characteristic of low levels of radiation damage. Second, radiation damage depletes in general the luminescence of minerals, which is associated with broadenings and intensity losses of individual emission lines. Minerals that have suffered elevated levels of irradiation hence tend to be virtually non-luminescent.

This review paper aims at giving an overview of the possible correlations of radiation damage and emission characteristics of minerals. After a brief, introductory summary of the damage-accumulation process and its causal corpuscular radiation, an array of examples is presented for how internal and/or external irradiation may change appreciably the emission of rock-forming and accessory minerals. As a detailed example for the complexity of changes of emissions upon damage accumulation, preliminary results of a case study of the photoluminescence (PL) of synthetic $\mathrm{CePO}_{4}$ irradiated with $8.8 \mathrm{MeV}$ He ions are presented. Irradiation-induced spectral changes include (i) the initial creation, and subsequent depletion, of a broad-band, defect-related PL emission of orange colour, and (ii) gradual broadenings and intensity losses of PL lines related to electronic transitions of rare-earth elements, eventually leading to gradual loss of their splitting into multiple Stark levels (shown for the ${ }^{4} \mathrm{~F}_{3 / 2} \rightarrow{ }^{4} \mathrm{I}_{9 / 2}$ transition of $\mathrm{Nd}^{3+}$ ).
\end{abstract}

Keywords Radiation damage $\bullet$ Ion irradiation • Defect centres • Radio-haloes • Photoluminescence $\bullet$ Cathodoluminescence 


\section{Introduction: Radiation damage in minerals}

The common phenomenon of structural radiation damage in minerals is predominantly due to atomic displacements that are caused by alpha decays of radio-nuclides (i.e., uranium and thorium, and their instable daughter nuclei). The beta-decay events in the same decay chains, and gamma radiation, are in general considered insignificant for the creation of permanent structural damage though the displacement of lattice atoms. The spontaneous fission of ${ }^{238} \mathrm{U}$, in contrast, produces a high amount of localised damage; this process is nevertheless negligible in considering bulk damage because of its relative rarity.

In discussing the action of alpha-decay events, two different types of radiation are to be considered (Fig. 1). An instable, heavy parent nucleus A emits spontaneously an alpha particle (i.e., a helium core) and hence transforms into a daughter nucleus $\mathrm{B}$, according to:

$$
{ }_{\mathrm{Z}}^{\mathrm{M}} \mathrm{A} \rightarrow{ }_{\mathrm{Z}-2}^{\mathrm{M-4}} \mathrm{B}+{ }_{2}^{4} \mathrm{He}
$$

A huge amount of energy, on the order of several millions of electron volts, is released in such an event. Its two main products, namely the alpha particle emitted and the heavy daughter nucleus, acquire the same impetus. Because of its ca. 50-fold higher weight, the heavy daughter nucleus carries away only about $2 \%$ of the energy (0.06-0.17 MeV), compared to that of the alpha particle (3.9-8.8 MeV). The recoil energy however still exceeds by several orders of magnitude the binding and displacement threshold energies of lattice atoms. The daughter nucleus is therefore displaced from the original lattice site of its parent, and travels though the host lattice.

To visualise, for the example of the alpha decay of ${ }^{212} \mathrm{Po}$, the different trajectory lengths of the recoil nucleus and the alpha particle emitted, and the different profiles of their nuclear and electronic interactions (i.e., atomic displacements and lattice ionisation, respectively) in the host mineral, Monte Carlo simulations were done of the stopping of 0.17 $\mathrm{MeV}^{208} \mathrm{~Pb}$ and $8.8 \mathrm{MeV}^{4} \mathrm{He}$ ions in a $\mathrm{CePO}_{4}$ target. The calculations were done using the SRIM-2008 code (Ziegler et al. 2008). This software package (SRIM = the Stopping and Range of Ions in Matter) is based on a full quantum-mechanical treatment of ion-atom collisions; it predicts, among others, the ranges of the ions irradiated, and density and distribution of the vacancies generated in the target (Ziegler et al. 1985). The density of atoms in the target was assumed to be $8.145 \times 10^{22} \mathrm{~cm}^{-3}\left(\rho=5.3 \mathrm{~g} / \mathrm{cm}^{3}\right)$. The SRIM default values were accepted for displacement threshold (Ce and P, $25 \mathrm{eV}$; $\mathrm{O} 28 \mathrm{eV}$ ), lattice binding ( $3 \mathrm{eV}$ ), and surface binding energies (3.3-4.2 eV). To reach high statistical precision, trajectories for 10,000 incoming ions, irradiated into the target perpendicular to its surface, were calculated. Selected results are presented in Fig. 1.

The $0.17 \mathrm{MeV}$ recoil nucleus loses a significant fraction of its energy in nuclear interactions (i.e., elastic collisions with lattice atoms; Fig. 1). Including multiple atomic displacements within sub-branches created by the displaced lattice atoms, each recoiled nucleus thus creates a tiny damage cluster. This cluster is less than $100 \mathrm{~nm}$ in length (compare Weber 1990; Weber et al. 1994; Shpak et al. 2007). According to our SRIM results it contains an average of $\sim 2000$ atomic displacements (Fig. 1). The $8.8 \mathrm{MeV}$ alpha particle, in contrast, travels more than 30,000 nm through the monazite target. Throughout its pathway it loses the vast majority of its high energy though electronic interactions, and 200 scattered Frenkeltype defects (i.e., vacancy-interstitial pairs) are created predominantly near the far ends of the ion trajectories (cf. Weber et al. 1998; Ewing et al. 2003; Fig. 1). It should be noted that among the common alpha-decay events in the U-Pb and Th-Pb chains, the ${ }^{212} \mathrm{Po}$ decay 
releases the highest energy. The recoiled ${ }^{208} \mathrm{~Pb}$ therefore creates the largest defect cluster with the highest number of defects; the same is true for the alpha particle created in this event.

It should be noted that the number of defects in the ballistic collision cascade caused by a heavy recoil nucleus is still a contended issue. For instance, Devanathan et al. (2006) found that an average of $\sim 6000$ defects are created per alpha recoil in zircon, whereas SRIM calculations of Nasdala et al. (2001) predicted an average of only 1000 defects per recoil cluster. Predictions of the amounts of defects based on SRIM calculations should therefore be considered as rather rough estimates (for instance, the anisotropy of the target lattice remains unconsidered, and default energies were used). More reliable predictions require the application of molecular dynamics (MD) simulations (Trachenko et al. 2004; Devanathan et al. 2006; Shpak et al. 2007). As an example for a MD result, a picture of the damage cluster created by a heavy nucleus is shown in Figure 2. It can be seen clearly that its central, densitydepleted amorphous part is surrounded by a region where the host lattice is compacted and affected by shear stress and shows high concentrations of point defects (for details cf. Trachenko et al. 2002).

In spite of significant simplifications and the resulting uncertainties, our SRIM results (Fig. 1) nevertheless indicate that minerals incorporating the radio-nuclides $U$ and $T h$ in their lattices, suffer structural damage mainly due to the action of alpha recoils (cf. Wasiliewski et al. 1973). The alpha particles themselves have rather subsidiary contribution (i.e., ca. 10$15 \%)$ to the total bulk damage. Due to the comparably minor damage efficiency but much longer range of the alphas emitted, compared to the recoiled nuclei, alpha particle damage is mostly observed in non-radioactive minerals as a result of external irradiation. This irradiation may emanate either from $U$ - or Th-containing phases that are included within the mineral, or radioactive sources (minerals or fluids) in close proximity. For U- or Th-bearing minerals, notable alpha-particle damage has been described only in few cases, for instance near boundaries between zones or interior regions that show huge relative differences in the radionuclide concentrations (for heterogeneous zircon shown by Nasdala et al. 2005).

The metamictisation process, i.e., build-up of bulk damage in actinide-bearing minerals, is based on the accumulation of numerous recoil clusters (plus scattered point defects) over geologic periods of time. The corpuscular irradiation itself - in mineralogical papers commonly expressed by the time-integrated alpha dose (Holland and Gottfried 1955; Murakami et al. 1991; Nasdala et al. 2001) - is however, inappropriate to "quantify" the radiation damage of a certain mineral. First, irradiation effects (i.e., the efficiency of a certain corpuscle in generating damage) may vary appreciably depending on the mineral species irradiated. Second, and most importantly, irradiation effects vary appreciably depending on the temperature (Meldrum et al. 1999; Nasdala et al. 2001). Note that a high number of alphadecay events is merely an essential presumption for, but does not necessarily result in, the formation of bulk damage. Whether or not the structural damage created in alpha-decay events is stored and accumulated by the host mineral depends on the temperature-dependent ratio between damage generation and damage annealing.

We attempt to visualise the resulting different behaviours of minerals with two arrays of sketches in Figure 3. At temperatures where annealing is insignificant, or at least exceeded by the rate of damage creation, the recoil damage is accumulated (Fig. 3, upper row). At low irradiation levels, the crystalline host mineral shows isolated recoil clusters (plus scattered point defects). At elevated irradiation levels, the damage clusters inter-connect and form a three-dimensional network. This process is referred to as percolation transition (Salje et al. 1999; Trachenko et al. 2004); it is connected with dramatic changes in the diffusion 
behaviour. Upon further damage accumulation, the bulk crystalline phase collapses and isolated crystalline remnants in an amorphous matrix are observed; and eventually the material becomes amorphised. This sequence (compare also Murakami et al. 1991) describes - widely simplified - the metamictisation process, as it is observed commonly for minerals such as pyrochlore, tetragonal $\mathrm{ThSiO}_{4}$, or zircon. The prerequisite for the damage accumulation is that these minerals must have spent a sufficiently long period at sufficiently low temperatures (for zircon below $150-200{ }^{\circ} \mathrm{C}$; Meldrum et al. 1998; 1999). Still, the alpha dose experienced by the respective mineral since the time of its growth cannot be expected from the outset to correlate with the damage present. In fact, the majority of natural zircon was found to be less radiation-damaged than it would correspond to complete accumulation of the alpha-event damage (Nasdala et al. 2004).

At elevated temperatures, or for minerals that undergo self-annealing at low temperatures already (for instance monazite-group phosphate minerals or monoclinic $\mathrm{ThSiO}_{4}$ ), the annealing rate exceeds the rate of creation of irradiation-induced damage. As a result, the damage cannot be accumulated (the structural recovery is visualised in Fig. 3, lower row, as "fading" of damage clusters). For example, monazite-(Ce) has, to the best of our knowledge, never been found in a severely radiation-damaged or even fully metamict state (Seydoux-Guillaume et al. 2007; Ruschel et al. 2012), in spite of the mostly much higher actinide concentrations and alpha doses of this mineral, compared to zircon.

Provided the thermal annealing does not prevail, the alpha-decay damage is accumulated. The above description is however guilty of some simplification, as in addition to the two competing processes of immediate annealing and crystalline-to-amorphous transition as a result of damage accumulation, other processes need to be taken into consideration also. First, there are always moderate irradiation-induced chemical changes, because in alpha-decay events the parent element transmutes into a daughter element and helium is produced. Also, the corpuscular "bombardment" of the target may result in segregation and phase or molecular decomposition. Examples include the irradiation-induced transformation of $\gamma-\mathrm{Fe}_{2} \mathrm{SiO}_{4}$ into $\mathrm{Fe}_{3} \mathrm{O}_{4}$ and $\mathrm{SiO}_{2}$ (Wang et al. 1999), decomposition of $\mathrm{HfSiO}_{4}$ and $\mathrm{ZrSiO}_{4}$ into component oxides (Meldrum et al. 1999), or conversion of $\mathrm{CO}_{2}$ molecules in cordierite into $\mathrm{CO}$ and $\mathrm{O}_{2}$ (Nasdala et al. 2006a; Krickl et al. 2009b; Weikusat et al. 2010). In the study of radiation-damage effects, one is obliged to survey cautiously as to which degree such irradiation-induced changes may have affected the radiation-damaged mineral under investigation.

The structural and chemical changes caused by the self-irradiation result in dramatic changes of the mineral's solid-state properties. Apart from significant changes of many physical parameters (such as refraction, hardness, density, and elastic moduli; see for instance Holland and Gottfried 1955; Vance and Milledge 1972; Chakoumakos et al. 1991; Dooley et al. 1993), the chemical resistance of radiation-damaged minerals is typically decreased, resulting in enhanced susceptibility to secondary alterations and chemical changes (e.g., Balan et al. 2001; Mathieu et al. 2001; Geisler et al. 2003; 2005; Nasdala et al. 2010b). Care should however be taken in discussing direct and indirect irradiation effects. The latter comprises changes that are not caused by the irradiation and the resulting structural damage itself, but by subsequent processes such as secondary alteration. However, radiation damage decreases a mineral's chemical resistance and hence favours chemical alterations, but it does not cause such processes. Elemental, textural, and colour changes caused by a fluid-driven reaction, for instance, therefore cannot be considered as direct irradiation effects. 
The decreased resistance of radiation-damaged minerals in potential post-growth processes is of enormous importance, as it for instance affects negatively their performance to immobilise radioactive elements (storage of nuclear waste) or to retain radiogenic nuclei (bias of geochronology results). The former is probably the main motivation for the extensive research done on radiation-damaged minerals and their synthetic analogues during the past two decades. Such secondary irradiation effects will nevertheless not be summarised here. The following discussion of irradiation-induced changes of the emission behaviour of minerals focuses on direct irradiation effects, i.e., changes in radiative electronic transitions that are due to modifications of the structure as caused by the impact of corpuscular radiation.

\section{Radiation-damage effects on the luminescence of minerals}

Possible effects of corpuscular radiation on the luminescence of minerals are still discussed somewhat controversially by Earth scientists. On the one hand, structural damage is known to suppress in general the emission performance of crystals (e.g., Vaz and Senftle 1971; Geisler and Pidgeon 2001; Seydoux-Guillaume et al. 2002; Nasdala et al., 2009; Ruschel et al. 2010). On the other hand, damage may enhance the emission, as observed from the strongly luminescent radio-haloes in naturally non- or weakly luminescent minerals (e.g., Smith and Stenstrom 1965; Mendelssohn et al. 1979; Schertl et al., 2004; Botis et al., 2005; Kagi et al. 2007). These two trends are only apparently contrarious; they are merely due to two different irradiation-induced phenomena which may even be affected simultaneously. They are summarised in the following and illustrated with examples (Fig. 4).

It is well-known that irradiation-damage in minerals may reduce notably their emission performance as detected by ionoluminescence (e.g., Garcia-Guinea et al. 2007; Nagabhushana et al. 2008) and thermoluminescence (e.g., Vaz and Senftle 1971). Please note, however, that these techniques are not discussed in detail here; our summary focuses on effects of irradiation damage in minerals on the two luminescence techniques that are used most commonly in the study of geological materials, namely, photoluminescence (PL) and cathodoluminescence (CL).

Most rock-forming and accessory minerals are insulator crystals. Such materials (provided they are chemically pure and well-crystalline) do not emit visible luminescence due to "intrinsic" band-band electronic transitions, because their forbidden band gap corresponds to quantum energies in the ultraviolet (UV) range. Luminescence of insulator-type minerals is however commonly observed owing to the presence of additional electronic levels within the band gap, which may for instance be caused by traces of non-formula chemical constituents, vacancies, or structural distortions. Such deviations from the ideal chemical and structural composition may also be created by the impact of radioactivity (or other forms of irradiation, such as the impact of the high-energy electron beam during electron probe micro-analysis). One potential effect of corpuscular irradiation is therefore the introduction of electronic activator levels into the band gap through the creation of defect centres (i.e., vacancies, interstitials, valence changes; or combinations of them).

One of the most common and striking example for defect luminescence is that of $\alpha-$ quartz. Structural damage in this mineral as caused by the impact of alpha-irradiation is easily detected in cathodoluminescence (CL) images obtained in CL systems attached to an optical microscope (OM-CL). Here, the damage is observed in the form of yellowish-orange radiohaloes (Owen 1988; Ramseyer et al. 1988; Meunier et al. 1990; Götze et al. 2001; Krickl et al. 
2008; Okumura et al. 2008). The sources of the alpha radiation are mostly inclusions of actinide-bearing minerals (Fig. 4a), however external alpha-irradiation caused by neighbouring phases such as radioactive fluids (Fig. 4b) are also observed. As alpha particles in the natural $U$ and Th decay chains penetrate about 10-45 $\mu \mathrm{m}$ in $\alpha$-quartz, luminescent radio-haloes in this mineral typically have diameters of several tens of micrometres (Komuro et al., 2002; Botis et al., 2005; Krickl et al., 2008). The orange colour of the CL emission was assigned by Siegel and Marrone (1981) to non-bridging oxygen-hole centres generated by the impact of alpha particles. An analogous (however much more rarely observed) example for luminescent radio-haloes was documented by Schertl et al. (2004), namely, blue emission of kyanite related to alpha-particle damage in close proximity to radioactive monazite (Fig. 4c).

In addition to the investigation of radio-haloes in naturally irradiated minerals, defectluminescence phenomena are studied increasingly from samples that were irradiated with beams of ions. As discussed above, the investigation of natural samples always bears the uncertainty that, due to a possibly unknown or uncertain thermal history, estimates of the amounts of irradiation that have caused effectively the defect luminescence observed are potentially biased. Irradiations in the laboratory (especially if done at very low temperatures), in contrast, allow one to exclude post-irradiation annealing and hence provide a more reliable tool for the quantification of irradiation effects. Examples for the generation of defect luminescence in irradiation experiments are presented in Figures $4 \mathrm{~d}-\mathrm{f}$.

Alpha irradiation of diamond followed by moderate heating at temperatures in the range $500-1000{ }^{\circ} \mathrm{C}$ causes, in addition to transformation of the green into orange-brown radio-colouration (Vance et al. 1973), intense yellowish green defect luminescence (Fig. 4d). The emission is mainly assigned to the $\mathrm{H} 3$ centre (i.e., two $\mathrm{N}$ atoms associated with a vacancy; see Zaitsev 2001, and references therein). This centre's zero-phonon line lies near $19870 \mathrm{~cm}^{-1}$ (503.2 nm wavelength), with several intense electron-phonon coupling bands in the range $>18900 \mathrm{~cm}^{-1}$ (<529 $\mathrm{nm}$ wavelength). It forms when upon thermal annealing the irradiation-induced GR1 centre (i.e., a neutral vacancy) becomes mobile and is trapped at an A defect (i.e., a nitrogen pair; Alekseev et al. 2000; Collins et al. 2005; Collins and Kiflawi 2009). A similarly strong activation of defect luminescence (however of yellow colour) is observed upon alpha irradiation of zircon (Fig. 4e). The emission centre is related to point defects created by the alpha particles (Götze et al. 1999; Gaft et al. 2002; Nasdala et al. 2011); however its exact assignment is still somewhat controversial. The OM-CL image presented in Figure 4e shows a synthetic $\mathrm{ZrSiO}_{4}$ crystal after comparably heavy He irradiation (fluence $10^{16}$ ions per $\mathrm{cm}^{2}$ ). The surficial damaged volume emits intense defect luminescence. Nasdala et al. (2011) found in He-irradiation experiments that this broad-band yellow CL is generated at very low, and suppressed at moderate defect densities. This conclusion is underlined by the fact that the yellow emission has only been observed for natural zircon with very low degrees of radiation damage (Hanchar et al. 1997; Götze et al. 1999). A third example for irradiationinduced emission is shown in Fig. 4f. Though this example is not related to corpuscular but electron irradiation, we show it here because it demonstrates nicely how irradiation-related damage may result in significant defect luminescence. The surface of this polished epoxy mount, containing synthetic $\mathrm{CePO}_{4}$ crystals, shows extensive electron-beam damage. Each single imaging scan in the scanning electron microscope (SEM) can be recognised as rectangular area. The intensity of the emission seems to correlate with the intensity of the beam impact and damage, as slower and hence longer scans have produced brighter rectangles (see especially the interlaced small rectangles near the bottom of the image). 
Examples for the opposite effect of luminescence suppression due to irradiation damage are presented in Figs. 4g-j. Radio-haloes in feldspar do not show any radiocolouration (Fig. 4g, left part) but are characterised by CL colour changes (Fig. 4g, right part). In most cases a significant depletion of the CL emission intensity is observed. Un-irradiated feldspar typically shows pale blue CL. This emission colour is mainly due to a broad band near 20800-22200 $\mathrm{cm}^{-1}$ (450-480 nm wavelength), which is assigned to paramagnetic oxygen point-defects (such as the Al-O-Al centre; Finch and Klein 1999; Götze et al. 2000). In alpha haloes the intensity of this band is decreased appreciably (Krickl et al. 2009a) whereas a reddish-brown colour component of the emission is observed. The latter was found to be due to new radiation-induced bands near 16600-17800 $\mathrm{cm}^{-1}$ (560-600 nm wavelength;

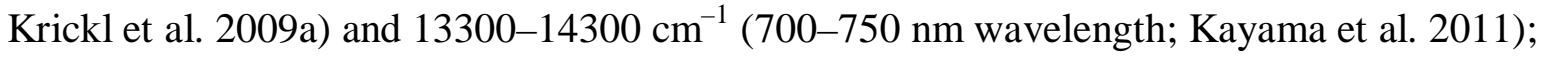
sound band assignments however cannot be given at present.

The irradiation-induced intensification of the emission of diamond has been described above (cf. Fig. 4d), the opposite effect is shown in Fig. 4h. Brown coloured radio-haloes at the surface of a rough diamond specimen appear dark under UV illumination; the blue PL of the un-irradiated host is depressed in these areas as a result of relatively strong alpha irradiation. More weakly alpha-irradiated areas, in contrast, show the yellowish-green defect PL (note that in Fig. 4h, all dark spots are surrounded by irregularly shaped PL haloes). Defect-PL in diamond seems hence to follow the same general behaviour as the defect-CL in zircon described above, namely, creation at very low defect densities and suppression at elevated defect densities. This was recently confirmed in ion-irradiation experiments on diamond conducted by Nasdala et al. (2013).

A typical example for the general inverse correlation of radiation damage and integral emission intensity is presented in Fig. 4i, which compares the birefringence and SEM-CL patterns of a complex zircon crystal containing an inner and an outer core. Only the outer core is mildly radiation-damaged, whereas inner core and outer regions are strongly damaged (Nasdala et al. 2005). Correspondingly, only the outer core shows "fresh" $3^{\text {rd }}$ order interference colours (note that the birefringence decreases strongly with increasing radiation damage; Sahama 1981; Chakoumakos et al. 1987) and appears bright in the CL image. It could of course be speculated that the lowered CL of this crystal's inner core and outer region is not due to their more elevated damage but alternatively caused by differences in the chemical compositions. Such uncertainties are excluded for the example presented in Fig. 4j, which is discussed in the following.

In addition to the artificial creation of radiation damage through ion-irradiation in the laboratory, the effect of radiation damage in minerals on their luminescence behaviour is studied commonly in thermal annealing experiments. It is well known that the structural reconstitution of initially radiation-damaged minerals results in significant increases of their integral emission (Geisler and Pidgeon 2001; Nasdala et al. 2002; Seydoux-Guillaume et al. 2002). In such studies, mineral samples are mostly analysed under the very same conditions before and after the annealing. Nasdala et al. (2006b) followed a different concept. In their study, accessory zircon grains were cut in half, one of the half-crystals was annealed (whereas the other half-crystal was left in the original, radiation-damaged state), and both half-crystals were then prepared close to each other in one mount. This procedural manner was connected with the two analytical advantages. First, two half-crystals of the same original (i.e., objects with corresponding internal textural patterns and chemical compositions) were compared. Second, the preparation provided the option to study the back-scattered electrons (BSE) and CL intensities of the two half-crystals simultaneously in one single imaging step, under truly 
identical conditions. It can be seen in Fig. $4 \mathrm{j}$ that the structural reconstitution of zircon is not only connected with BSE decrease (assigned tentatively by Nasdala et al. 2006b to electronchannelling contrast) but also a significant increase of the CL.

The recovery of the emission behaviour upon structural reconstitution is also demonstrated in Fig. 5, showing three pairs of PL spectra of minerals rich in rare-earth elements (REE). Strongly radiation-damaged (amorphous) fergusonite-(Y) (Fig. 5a; Ruschel et al. 2010) and ekanite (Fig. 5c) are characterised by nearly complete suppression of REErelated emissions, which are recovered after annealing, leading to dramatic increases of the integral emission. Similar recovery of the REE-related CL (Nasdala et al. 2002) and PL emissions (Nasdala et al. 2004) was observed upon recrystallisation through thermal annealing of naturally amorphised zircon. Moderately radiation-damaged monazite-(Ce) shows REE more or less “intact” emissions (Fig. 5b). However individual Stark levels of electronic transitions are somewhat broadened, reflecting disturbance of the short-range order around the REE sites. Upon annealing, a general sharpening of the individual lines is observed, along with moderate intensity gain (Fig. 5b). Similar line sharpening and intensity gain of $\mathrm{Nd}^{3+}$-related emissions upon annealing of radiation-damaged aeschynite-group minerals has been reported already by Xue and Gong (2000).

The examples above covered effects of the main radiation-induced process, i.e., the gradual transformation of a crystalline material to its amorphous analogue, on its emission characteristics. Additional processes such as irradiation-induced chemical changes, irradiation-induced segregation, phase decomposition, or secondary chemical and structural changes, have not been underlined with examples; nevertheless they need to be considered, if applicable, in interpreting the emission phenomena observed. For instance, radiogenic daughter elements, implanted in the host mineral, could hypothetically form emission centres (for instance, Pb-related luminescence is well-known; Gaft et al. 2005 and references therein). Also, the secondary uptake of non-formula constituents upon chemical alteration may suppress the emission and/or introduce elemental species that form new emission centres. To give an example for the former, it is known that dehydration of solids may increase their emission intensity (Gutzov and Peneva 1995). The secondary uptake of water in a secondary, fluid-driven alteration of a radiation-damaged mineral may therefore be expected to result in suppression of the emission. Also, as the primary radiation-damaged phase is decomposed and a secondary phase crystallises, alteration events are typically connected with an increase of the crystallinity, which in turn may also increase the emission.

Most irradiation-induced changes of the luminescence of self- or externally irradiated, insulator-type minerals, however, are related to the introduction of defects in the structure due to atomic knock-ons. The spectral changes observed include (i) general intensity losses (generally assigned to either the decreasing short-range order around existing centres or the formation of non-radiative recombination centres) connected with broadenings of individual emission lines, and/or (ii) also intensity gains due to either irradiation-induced restructuring (e.g., Bhave et al. 1999) or the creation of new emission centres. 


\section{Study of helium-irradiated $\mathrm{CePO}_{4}$}

\section{Generalities and experimental details}

Although the thorough characterisation of the luminescence of naturally radiation-damaged minerals may provide a wealth of useful information, the uncertainty remains how much of irradiation was needed to create the damage present, and hence the luminescence changes observed? This uncertainty is underlined by the consideration that the irradiation dose experienced by a certain sample, and the damage accumulated by this sample, do not necessarily correlate. Rather there is often a clear mismatch between damage creation and storage, due to thermal annealing and hence partial or even complete structural reconstitution. Quantitative studies, i.e. those addressing the question how much of corpuscular irradiation is needed to create certain changes of the luminescence behaviour, require samples with wellknown thermal histories. This is the case for samples whose radiation damage was generated under controlled conditions in the laboratory, through irradiation with ion beams. As an example for the latter, preliminary results of a study of synthetic, monazite-structured $\mathrm{CePO}_{4}$ irradiated with ${ }^{4} \mathrm{He}$ ions, are reported in the following.

The sample investigated consisted of crystals of monoclinic $\mathrm{CePO}_{4}$ (space group $P 2_{1} /$,, $\mathrm{Z}=4$ ), synthesised using a lithium molybdate flux-type method (Hanchar et al. 2001; Ruschel et al. 2012). Preliminary X-ray diffraction and spectroscopic analyses showed that the crystals are very well ordered. Helium-irradiation experiments were done using unprepared $\mathrm{CePO}_{4}$ crystals, as these showed flat crystal faces of exceptionally high surface quality. Experiments were done at the nuclear reaction analysis beamline of the former $5 \mathrm{MV}$ Tandem accelerator (in the meantime decommissioned and replaced by a $6 \mathrm{MV}$ Tandetron accelerator) of the Helmholtz-Zentrum Dresden (formerly Forschungszentrum Rossendorf), Germany. Samples were attached to a copper sample-holder and loaded into a vacuum chamber ( $\sim 10^{-8}$ mbar). Irradiations were done at liquid-nitrogen temperature $\left(-196{ }^{\circ} \mathrm{C}\right)$ to exclude local up-warming of the sample under the focused beam and hence immediate thermal annealing during the experiment. The ion beam was focused to a rectangular area of about $1 \mathrm{~mm}^{2}$ size. Samples were irradiated with $8.8 \mathrm{MeV}^{4} \mathrm{He}^{2+}$ ions (this ion energy is equivalent to the energy of alpha particles produced in the ${ }^{212} \mathrm{Po} \rightarrow{ }^{208} \mathrm{~Pb}$ decay within the ${ }^{232} \mathrm{Th}$ chain). Irradiation fluences were varied in the range $1 \times 10^{14}-1 \times 10^{16} \mathrm{ions} / \mathrm{cm}^{2}$, which was achieved by varying the irradiation times between $\sim 30$ seconds and $\sim 50$ minutes.

The crystals irradiated were embedded in epoxy and cut parallel to the direction of the ion beam (i.e., roughly perpendicular to the surface irradiated). Thin sections (thicknesses $\sim 25$ $\mu \mathrm{m})$ attached to a glass side but without glass cover were produced. Thin sections were inspected first under visible light using an optical binocular microscope. Second, PL images (>400 nm wavelength) were obtained under broad UV (<370 nm wavelength) illumination using a mercury lamp.

Photoluminescence spectra in the visible and near-infrared range (i.e., spectral range 21000-10600 $\mathrm{cm}^{-1}$ ) and Raman spectra, both including confocal point-to-point line-scans with a step width of $1 \mu \mathrm{m}$, were obtained by means of a dispersive Horiba Jobin Yvon LabRam-HR spectrometer. This system was equipped with an Olympus BX41 optical microscope, a diffraction grating with 1800 grooves/mm in the optical pathway, a Si-based, Peltier-cooled charge-coupled device (CCD) detector, and a software-controlled x-y stage. The PL spectra were excited with the $473 \mathrm{~nm}$ emission of a diode laser ( $3 \mathrm{~mW}$ at the sample); 
Raman measurements were made with He-Ne $632.8 \mathrm{~nm}$ excitation (8 mW). With a 100x objective (NA $=0.90)$ used, and the system operated in the confocal mode, the lateral resolution was ca. $1 \mu \mathrm{m}$. Spectra were calibrated using the Rayleigh line and neon lamp emissions. The wavenumber accuracy was better than $0.5 \mathrm{~cm}^{-1}$, and the spectral resolution was determined at $\sim 1 \mathrm{~cm}^{-1}$. Fitting was done assuming Lorentzian-Gaussian shapes of individual bands/lines. Fit results for the full width at half maximum (FWHM) of bands were corrected mathematically for the apparatus function according to the simplified procedure of Dijkman and van der Maas (1976).

\section{Irradiation-induced damage}

Thin-sections of irradiated samples, prepared parallel to the direction of the incident ion beam, were inspected under a high-power optical microscope. In plane-polarised light, the area irradiated with $10^{16} \mathrm{He} / \mathrm{cm}^{2}$ showed a colourless but nevertheless clearly recognisable, narrow stripe-like feature parallel to the ion-irradiated surface (not shown). In the area irradiated with $10^{15} \mathrm{He} / \mathrm{cm}^{2}$, the stripe was still well recognised but faint, and in the area irradiated with $10^{14} \mathrm{He} / \mathrm{cm}^{2}$ it was hardly observable. At high magnification, the stripes appeared to consist of two parallel lines (inter-distance on the order of only 1-2 $\mu \mathrm{m}$ ) with mirror-inverted dark-bright contrast. In cross-polarised light, the narrow stripes showed significantly $\left(10^{16} \mathrm{He} / \mathrm{cm}^{2}\right)$ to slightly $\left(10^{15} \mathrm{He} / \mathrm{cm}^{2}\right)$ lowered interference colours, compared to the surrounding areas. Such features have been described already for other He-irradiated, colourless minerals such as $\alpha$-quartz (Krickl et al. 2008) or zircon (Nasdala et al. 2011). The stripe is interpreted as a narrow zone with clearly higher defect concentration, compared to the neighbouring volume areas. It is observed in transmitted light because the correspondingly higher radiation damage results in lowered refraction and birefringence (Holland and Gottfried 1955) and may hence be interpreted as a close pair of (mirror-inverted) Becke lines. In view of the theoretical defect distribution of $8.8 \mathrm{MeV}$ He ions in a $\mathrm{CePO}_{4}$ target (see Fig. 1), the stripe marks the volume area near the ends of the ion trajectories, where most of the damage (i.e., the majority of scattered Frenkel defect pairs) is created. In our case, the distance of the stripe from the surface irradiated was about 33-34 $\mu \mathrm{m}$, which corresponds very well with the depth of maximum damage as predicted by Monte Carlo calculation ( 33.6 $\mu \mathrm{m}$; Fig. 1).

Monoclinic $\mathrm{CePO}_{4}$ contains 24 atoms per unit cell (volume $\sim 300 \AA^{3}$ ), which converts to $\sim 8 \times 10^{-2}$ lattice atoms per $\AA^{3}$. Our SRIM calculations predicted that in the depth range 33$34 \mu \mathrm{m}$ below the sample surface, each $8.8 \mathrm{MeV}$ He ion creates an average of $7 \times 10^{-3}$ atomic displacements per $\AA$ of path length (Fig. 1). For the highest irradiation in our study $\left(10^{16}\right.$ $\mathrm{He} / \mathrm{cm}^{2}$ ), this value converts to a maximum defect concentration $7 \times 10^{-3}$ defects per $\AA^{3}$. The ratio of the two values above (i.e., $\sim 8 \times 10^{-2}$ lattice atoms and $7 \times 10^{-3}$ defects per $\AA^{3}$ ) suggests that the defect density within the stripe is ca. 0.09 displacements per lattice atom (dpa) in case of the sample irradiated with $10^{16} \mathrm{He} / \mathrm{cm}^{2}$. In spite of the relative impreciseness of such estimates based on SRIM results (as we have discussed above), the consideration above implies that a defect density of 0.09 dpa must be well below the amorphisation threshold for monoclinic $\mathrm{CePO}_{4}$. This assessment is supported by the detection of moderately broadened Raman bands of crystalline $\mathrm{CePO}_{4}$ [Fig. 6; a maximum FWHM of only $6.1 \mathrm{~cm}^{-1}$ was determined for the $v_{1}\left(\mathrm{PO}_{4}\right)$ band], which implies rather moderate structural damage 
(compare Ruschel et al. 2012), and the observation of lowered interference colours but still no extinction.

Except from the stripe in the sample irradiated with $10^{16} \mathrm{He} / \mathrm{cm}^{2}$, the ion-irradiated samples studied here represent in general low to very low levels of structural radiation damage. In the sample irradiated with $10^{16} \mathrm{He} / \mathrm{cm}^{2}$, the volume range $0-32 \mu \mathrm{m}$ below the surface irradiated (i.e., the volume between surface and stripe) yielded very minor Raman band broadening of ca. $+0.2-0.3 \mathrm{~cm}^{-1}$ [Fig. 6; FWHMs of the $v_{1}\left(\mathrm{PO}_{4}\right)$ Raman band were determined at 2.1-2.2 $\mathrm{cm}^{-1}$, compared to $1.9 \mathrm{~cm}^{-1}$ in the un-irradiated host beyond the stripe]. The sample irradiated with $10^{15} \mathrm{He} / \mathrm{cm}^{2}$ experienced mild radiation damage within the stripe [maximum FWHM of the $v_{1}\left(\mathrm{PO}_{4}\right)$ Raman band $2.7 \mathrm{~cm}^{-1}$ ]. Potential structural changes of this sample in the depth range $<32 \mu \mathrm{m}$ behind the surface irradiated, and throughout the sample irradiated with $10^{14} \mathrm{He} / \mathrm{cm}^{2}$, were below the detection sensitivities of Raman spectroscopy (Fig. 6) and microscopy under cross-polarised light.

\section{Irradiation-induced changes of the luminescence}

The effects of the He irradiation on the luminescence of $\mathrm{CePO}_{4}$ were investigated by obtaining PL photomicrographs and spectra. Colour images of the PL light obtained under UV illumination are dominated by an irradiation-induced emission of orange to brownish yellow colour. The emission patterns (i.e., the depth profiles of the PL intensity) observed vary appreciably with the ion fluence. In the sample irradiated with $10^{15} \mathrm{He} / \mathrm{cm}^{2}$, only the stripe shows intense defect luminescence (Fig. 7, left image; a similar but extremely faint emission pattern was observed from the sample irradiated with $10^{14} \mathrm{He} / \mathrm{cm}^{2}$ ). In the sample irradiated with $10^{16} \mathrm{He} / \mathrm{cm}^{2}$, the entire ion-irradiated volume, however except the stripe, emits orange light (Fig. 7, right image). Both luminescence patterns correspond to the predicted distribution pattern of point defects created by $8.8 \mathrm{MeV}$ alpha particles. Our observations indicate first the creation of the orange emission centre at very low defect densities on the order of $4 \times 10^{-5} \AA^{-3}$ (or $0.0005 \mathrm{dpa}$ ). This centre is then suppressed at moderate defect densities exceeding ca. $1-2 \times 10^{-3} \AA^{-3}$ (or exceeding ca. $0.02 \mathrm{dpa}$ ). This behaviour is similar to that of defect emissions of He-irradiated zircon (CL study by Nasdala et al. 2011) and diamond (PL study by Nasdala et al. 2013). The observation of onset and suppression of the defect luminescence of He-irradiated $\mathrm{CePO}_{4}$ at comparably higher defect densities, compared to $\mathrm{ZrSiO}_{4}$, does not necessarily indicate substantially different responses of the two phases to the He-irradiation but may perhaps be explained by the different luminescence techniques used. Further studies of ion-irradiated $\mathrm{CePO}_{4}$, involving irradiations with a wider range of fluences and combined PL and CL analyses, are planned.

Comparison of the depth profiles presented in Figs. 6 and 7 shows that the orange emission is observed in mildly radiation-damaged micro-areas, characterised by low values of the FWHM of the $v_{1}\left(\mathrm{PO}_{4}\right)$ Raman band in the range $2-3 \mathrm{~cm}^{-1}$. More radiation-damaged $\mathrm{CePO}_{4}$, in contrast, seems to be affected by general luminescence suppression. Ruschel et al. (2012) found in a comprehensive annealing study of a range of monazite-(Ce) samples from locations worldwide that the broadening of their $v_{1}\left(\mathrm{PO}_{4}\right)$ Raman band due to the accumulated radiation damage (estimated roughly from the difference between total and chemical broadening) was between $+6.6 \mathrm{~cm}^{-1}$ and $+12.8 \mathrm{~cm}^{-1}$. Our results indicate that the generally poor luminescence emission of all samples of Ruschel et al. (2012) is probably explained by 
the too high degree of radiation damage in these samples, well beyond the suppression of the orange band.

In PL spectra (Fig. 8a), the orange emission is evident as broad band with a maximum in the range $16000-18000 \mathrm{~cm}^{-1}$ (555-625 nm wavelength). Photoluminescence line-scans (Fig. 8b) showed that the depth profile of the intensity of the orange broad-band emission (see again Fig. 7, left image) correlates with the predicted defect distribution, whereas there is no clear correspondence to the ionisation distribution (compare Fig. 1). The creation of the orange emission centre consequently must be related to the formation of atomic point defects.

Superimposed on the orange broad-band emission there are groups of narrow emission lines, which are assigned to REE-related centres (Fig. 8a). These are dominated by $\mathrm{Sm}^{3+}$ in the visible range, potentially overlaid by $\mathrm{Eu}^{3+}$ and $\mathrm{Pr}^{3+}$, and low-intensity emissions of $\mathrm{Nd}^{3+}$ near $11500 \mathrm{~cm}^{-1}$ (near $870 \mathrm{~nm}$ wavelength; Gaft et al. 2005, and references therein). Their origin is explained by very minor pollution of the commercial high-purity $\mathrm{CeO}_{2}$ used as starting material for the synthesis. With increasing damage, the REE-related emissions show gradual intensity losses and broadening of individual lines (Fig. 8c). The Stark splitting of electronic transitions, observed as groups of individual lines, is however still preserved. This corresponds to the still preserved crystalline state (with mild to moderate disorder) of our samples. The gradual intensity losses with increasing damage are possibly due to simple destruction of radiative centres (for instance discussed by Tringe et al. 2007), resulting in an enhanced fraction of non-radiative energy releases (for instance through the generation of phonons) in the increasingly disturbed solid. Also, it needs to be considered that the creation of new defect related centres may cause partial energy release in radiative electronic transitions outside the visible range (due to the introduction of additional energetic levels within the forbidden band gap). Ionisation effects (i.e., the irradiation-induced transformation of $\mathrm{Nd}^{3+}$ to another valence state) may also reduce the $\mathrm{Nd}^{3+}$ emission. The latter however appears less significant, as the distribution patterns of intensity loss (Fig. 8d) and electronic stopping (Fig. 1, right part, dashed graph) do not correlate.

Depth profiles of spectral parameters of REE-related emissions (Figs. 8d-e) showed that especially the FWHMs of individual lines depend closely on the defect concentration in the sample. For instance, the line-broadening profile of the $11590 \mathrm{~cm}^{-1}$ (863 nm wavelength) Stark sub-level of the ${ }^{4} \mathrm{~F}_{3 / 2} \rightarrow{ }^{4} \mathrm{I}_{9 / 2}$ emission of $\mathrm{Nd}^{3+}$ shows a remarkably close match with the predicted defect profile (Fig. 8e). This observation is interpreted to reflect the increasing disturbance of the short-range order around the eight-fold $\mathrm{REE}^{3+}$ sites in the monazite-(Ce) structure.

\section{Conclusion}

Photoluminescence spectroscopy and imaging was proven again to be most sensitive in detecting minute amounts of defects and structural damages. In the case of PL emissions related to defect centres with $4 f$ electronic configuration that consist of groups of narrow emission lines, the increasing widths of individual lines were found to be related most sensitively to structural disorder and defect concentration. It is therefore suggested that REErelated emissions may potentially be used to quantify the degree of radiation damage. For this, however, the availability of reliable calibration lines is a mandatory presumption. This includes the need of calibrations for (i) effects of the chemical composition (see the review 
article by Lenz et al. in this special issue) and (ii) effects of structural irradiation damage on PL spectral parameters. The latter will be addressed in future irradiation experiments.

Such ion-irradiations for the establishment of a luminescence-versus-damage calibration will however not be done using light but heavy ions. First, damage produced by the latter corresponds more closely to the damage in natural minerals (please recall that most of the structural damage in natural minerals is created by alpha-recoils of the heavy daughter nuclei). Second, light ions, in contrast to heavy ions, create a narrow zone of heavy damage bracketed by mildly damaged areas (see again Fig. 1). The thinness of this zone, compared to the lateral resolution of modern spectrometers, and the strong damage-density gradient within this zone, make it most difficult to correlate observed changes of spectral parameters with their corresponding defect densities. Heavy-ion irradiation therefore appears much more promising for studying damage-dependent changes of the emission, especially if the experimental setup ensures that the entire target is damaged and not underlaid by undamaged sample volumes (discussed in detail by Nasdala et al. 2010a).

Potential analytical advantages of a PL-based damage-estimation technique include its high lateral resolution on the micrometre scale and the opportunity to perform analyses nondestructively. Similar to the Raman-based quantification of radiation damage, an analogous PL-based technique would for instance enable one to obtain information on the degree of radiation damage even for tiny accessories in rock thin-sections. The PL-based damage estimation appears promising, as an alternative to confocal Raman spectroscopy, especially in the case of REE-containing mineral species whose Raman spectrum is characterised by comparably broad bands. In such cases such as titanite or rutile, difficulties to monitor FWHM increases of initially broad vibrational bands

Acknowledgements Thanks are due to D.W. Davis, J. Götze, J.M. Hanchar, J.W. Harris, A. Kronz, A. Massanek, A. Möller, I.V. Pekov, H.-P. Schertl, and C. Schnier for providing samples, spectra, and images; and to K. Trachenko for the permission to publish Figure 2. Sample preparation was done by A. Wagner. We are grateful to two anonymous reviewers for their constructive comments. Financial support was provided by the European Commission through Research Infrastructures Transnational Access (RITA) grant no. 025646, and the Austrian Science Fund (FWF), grants P20028-N10 and P24448-N19.

\section{References}

Alekseev AG, Amosov VN, Krasilnikov AV, Tugrainov SN, Frunze VV, Tsutskikh AYu (2000) Transformation of GR1 defects in annealed natural type IIa diamonds. Tech Phys Lett 26:1-7

Balan E, Neuville DR, Trocellier P, Fritsch E, Muller JP, Calas G (2001) Metamictization and chemical durability of detrital zircon. Am Mineral 86:1025-1033

Bhave TM, Hullavarad SS, Bhoraskar SV, Hedge SG, Kanjilal D (1999) FTIR studies of swift silicon and oxygen ion irradiated porous silicon. Nucl Instrum Meth B 156:121-124

Botis S, Nokhrin SM, Pan Y, Xu Y, Bonli T, Sopuck V (2005) Natural radiation-induced damage in quartz. I. Correlations between cathodoluminescence colors and paramagnetic defects. Can Mineral 43:1565-1580

Chakoumakos BC, Murakami T, Lumpkin GR, Ewing RC (1987) Alpha-decay-induced fracturing in zircon: The transition from the crystalline to the metamict state. Science 236:1556-1559

Chakoumakos BC, Oliver BC, Lumpkin GR, Ewing RC (1991) Hardness and elastic modulus of 
zircon as a function of heavy-particle irradiation dose. I. In situ $\alpha$-decay event damage. Radiat Eff Defect S 118:393-403

Collins AT (2005) Optical centres produced in diamond by radiation damage. New Diam Front C Tec 17:47-61

Collins AT, Kiflawi I (2009) The annealing of radiation damage in type Ia diamond. J Phys Condens Mat 21:364209

Devanathan R, Corrales LR, Weber WJ, Chartier A, Meis C (2006) Molecular dynamics simulation of energetic uranium recoil damage in zircon. Mol Simulat 32:1069-1077

Dooley SP, Jamieson DN, Prawer S (1993) $\mathrm{He}^{+}$and $\mathrm{H}^{+}$microbeam damage, swelling and annealing in diamond. Nucl Instrum Meth B 77:484-491

Ewing RC, Meldrum A, Wang LM, Weber WJ, Corrales LR (2003) Radiation effects in zircon. In: Hanchar JM, Hoskin PWO (eds) Zircon. Rev Mineral Geochem, vol 41. Mineral Soc Am, Washington DC, pp 387-425

Finch AA, Klein J (1999) The causes and petrological significance of cathodoluminescence emissions from alkali feldspars. Contrib Mineral Petr 135:234-243

Gaft M, Shinno I, Panczer G, Reisfeld R (2002) Laser-induced time-resolved spectroscopy of visible broad luminescence bands in zircon. Miner Petrol 76:235-246

Gaft M, Reisfeld R, Panczer G (2005) Modern luminescence spectroscopy of minerals and materials. Springer, Berlin Heidelberg New York, 356 pp

Garcia-Guinea J, Correcher V, Sanchez-Muñoz L, Finch AA, Hole DE, Townsend PD (2007) On the luminescence emission band at 340nm of stressed tectosilicate lattices. Nucl Instrum Meth A 580:648-651

Geisler T, Pidgeon RT (2001) Significance of radiation damage on the integral SEM cathodoluminescence intensity of zircon: an experimental annealing study. Neues Jb Miner Monat 2001:433-445

Geisler T, Trachenko K, Ríos S, Dove MT, Salje EKH (2003) Impact of self-irradiation damage on the aqueous durability of zircon $\left(\mathrm{ZrSiO}_{4}\right)$ : implications for its suitability as a nuclear waste form. $\mathrm{J}$ Phys Condens Matter 15:L597-L605

Geisler T, Seydoux-Guillaume A-M, Poeml P, Golla-Schindler U, Berndt J, Wirth R, Pollok K, Janssen A, Putnis A (2005) Experimental hydrothermal alteration of crystalline and radiationdamaged pyrochlore. J Nucl Mater 344:17-23

Götze J, Kempe U, Habermann D, Nasdala L, Neuser RD, Richter DK (1999) High-resolution cathodoluminescence combined with SHRIMP ion probe measurements of detrital zircons. Mineral Mag 63:179-187

Götze J, Krbetschek MR, Habermann D, Wolf D (2000) High-resolution cathodoluminescence studies of feldspar minerals. In: Pagel M, Barbin V, Blanc P, Ohnenstetter D (eds), Cathodoluminescence in geosciences. Springer, Berlin Heidelberg, pp 245-270

Götze J, Plötze M, Habermann D (2001) Origin, spectral characteristics and practical applications of the cathodoluminescence (CL) of quartz - a review. Miner Petrol 71:225-250

Gutzov S, Peneva SK (1995) Structure and properties of hydrous zirconium oxide. Bulg Chem Commun 28:744-751

Hanchar JM, Hoskin PWO, Jackson SG, Hinton RW, Thibault Y, Finch RJ, Wolf S, Watson EB, Hemming S, Hanson B, Lindstrom DJ (1997) Rare earth elements and the Ce anomaly in terrestrial zircons. EOS Trans Am Geophys Union 78:F783

Holland HD, Gottfried D (1955) The effect of nuclear radiation on the structure of zircon. Acta Cryst 8:291-300

Kagi H, Sato S, Akagi T, Kanda H (2007) Generation history of carbonado inferred from photoluminescence spectra, cathodoluminescence imaging, and carbon-isotopic composition. Am Mineral 92:217-224

Kayama M, Nishido H, Toyoda S, Komuro K, Ninagawa K (2011) Radiation effects on cathodoluminescence of albite. Am Mineral 96:1238-1247 
Komuro K, Horikawa Y, Toyoda S (2002) Development of radiation-damage halos in low-quartz: cathodoluminescence measurement after $\mathrm{He}^{+}$ion implantation. Miner Petrol 76:261-266

Krickl R, Nasdala L, Götze J, Grambole D, Wirth R (2008) Alpha-irradiation effects in $\mathrm{SiO}_{2}$. Eur J Mineral 20:517-522

Krickl R, Götze J, Grambole D, Kaindl R (2009a) Radiohaloes in feldspar group minerals. Hallesches Jahrb Geowiss 31:134

Krickl R, Nasdala L, Grambole D, Kaindl R (2009b) Radio-induced alteration in cordierite implications for petrology, gemmology and material science. Geophys Res Abstr 11 (Eur Geosciences Union General Assembly, Wien, 2009), EGU2009-2657-2

Mathieu R, Zetterström L, Cuney M, Gauthier-Lafaye F, Hidaka H (2001) Alteration of monazite and zircon and lead migration as geochemical tracers of fluid paleocirculations around the OkloOkélobondo and Bangombé natural nuclear reaction zones (Franceville basin, Gabon). Chem Geol 171:147-171

Meldrum A, Boatner LA, Weber WJ, Ewing RC (1998) Radiation damage in zircon and monazite. Geochim Cosmochim Ac 62:2509-2520

Meldrum A, Boatner LA, Zinkle SJ, Wang S-X, Wang L-M, Ewing RC (1999) Effects of dose rate and temperature on the crystalline-to-metamict transformation in the $\mathrm{ABO}_{4}$ orthosilicates. Can Mineral 37:207-221

Mendelssohn MJ, Milledge HJ, Vance ER, Nave E, Woods PA (1979) Internal radioactive haloes in diamond. Diamond Research 1979 (DeBeers Indust Diam Div), pp 31-36

Meunier JD, Sellier E, Pagel M (1990) Radiation-damage rims in quartz from uranium-bearing sandstones. J Sediment Petrol 60:53-58

Murakami T, Chakoumakos BC, Ewing RC, Lumpkin GR, Weber WJ (1991) Alpha-decay damage in zircon. Am Mineral 76:1510-1532

Nagabhushana H, Prashantha CS, Lakshminarasappa BN, Singh F (2008) Ionoluminescence and photoluminescence studies of $\mathrm{Ag}^{8+}$ ion irradiated kyanite. J Luminesc 128:7-10

Nasdala L, Wenzel M, Vavra G, Irmer G, Wenzel T, Kober B (2001) Metamictisation of natural zircon: accumulation versus thermal annealing of radioactivity-induced damage. Contrib Mineral Petr 141:125-144

Nasdala L, Lengauer CL, Hanchar JM, Kronz A, Wirth R, Blanc P, Kennedy AK, Seydoux-Guillaume A-M (2002) Annealing radiation damage and the recovery of cathodoluminescence. Chem Geol 191:121-140

Nasdala L, Reiners PW, Garver JI, Kennedy AK, Stern RA, Balan E, Wirth R (2004) Incomplete retention of radiation damage in zircon from Sri Lanka. Am Mineral 89:219-231

Nasdala L, Hanchar JM, Kronz A, Whitehouse MJ (2005) Long-term stability of alpha particle damage in natural zircon. Chem Geol 220:83-103

Nasdala L, Wildner M, Wirth R, Groschopf N, Pal DC, Möller A (2006a) Alpha particle haloes in chlorite and cordierite. Miner Petrol 86:1-27

Nasdala L, Kronz A, Hanchar JM, Tichomirowa M, Davis DD, Hofmeister W (2006b) Effects of natural radiation damage on back-scattered electron images of single-crystals of minerals. Am Mineral 91:1739-1746

Nasdala L, Kronz A, Wirth R, Váczi T, Pérez-Soba C, Willner A, Kennedy AK (2009) Alteration of radiation-damaged zircon and the related phenomenon of deficient electron microprobe totals. Geochim Cosmochim Ac 73:1637-1650

Nasdala L, Grötzschel R, Probst S, Bleisteiner B (2010a) Irradiation damage in monazite $\left(\mathrm{CePO}_{4}\right)$ : An example to establish the limits of Raman confocality and depth resolution. Can Mineral 48:351-359

Nasdala L, Hanchar JM, Rhede D, Kennedy AK, Váczi T (2010b) Retention of uranium in complexly altered zircon: An example from Bancroft, Ontario. Chem Geol 269:290-300

Nasdala L, Grambole D, Götze J, Kempe U, Váczi T (2011) Helium irradiation study on zircon. Contrib Mineral Petr 161:777-789 
Nasdala L, Grambole D, Wildner M, Gigler AM, Hainschwang T, Zaitsev AM, Harris JW, Milledge J, Schulze DJ, Hofmeister W, Balmer WA (2013) Radio-colouration of diamond: a spectroscopic study. Contrib Mineral Petr (DOI 10.1007/s00410-012-0838-1; published online).

Okumura T, Nishido H, Toyoda S, Kaneko T, Kosugi S, Sawada Y (2008) Evaluation of radiationdamage halos in quartz by cathodoluminescence as a geochronological tool. Quat Geochronol 3:342-345

Owen MR (1988) Radiation-damage halos in quartz. Geology 16:529-532

Ramseyer K, Baumann J, Matter A, Mullis J (1988) Cathodoluminescence colours of alpha-quartz. Mineral Mag 52:669-677

Ruschel K, Nasdala L, Rhede D, Wirth R, Lengauer CL, Libowitzky E (2010) Chemical alteration patterns in metamict fergusonite. Eur J Mineral 22:425-433

Ruschel K, Nasdala L, Kronz A, Hanchar JM, Többens DM, Škoda R, Finger F, Möller A (2012) A Raman spectroscopic study on the structural disorder of monazite-(Ce). Miner Petrol 105:4155

Sahama TG (1981) Growth structure in Ceylon zircon. Bull Minéral 104:89-94

Salje EKH, Chrosch J, Ewing RC (1999) Is “metamictization” of zircon a phase transition? Am Mineral 84:1107-1116

Schertl H-P, Neuser RD, Sobolev NV, Shatsky VS (2004) UHP-metamorphic rocks from Dora Maira/Western Alps and Kokchetav/Kazakhstan: New insights using cathodoluminescence petrography. Eur J Mineral 16:49-57

Seydoux-Guillaume A-M, Wirth R, Nasdala L, Gottschalk M, Montel JM, Heinrich W (2002) An XRD, TEM and Raman study of experimentally annealed natural monazite. Phys Chem Miner 29:240-253

Seydoux-Guillaume AM, Wirth R, Ingrin J (2007) Contrasting response of $\mathrm{ThSiO}_{4}$ and monazite to natural irradiation. Eur J Mineral 19:7-14

Shpak AP, Grechanovsky OY, Litovchenko AS, Sayenko SY (2007) Molecular dynamics simulation of displacement cascades in zircon. Probl At Sci Tech 2007(2):29-32 (in Russian)

Siegel GH, Marrone MJ (1981) Photoluminescence in as-drawn and irradiated silica optical fibres: An assessment of the role of non-bridging oxygen defect centers. J Non-Cryst Solids 45:235-247

Smith JV, Stenstrom RC (1965) Electron-excited luminescence as a petrologic tool. J Geol 73:627635

Trachenko K, Dove MT, Salje EKH (2002) Structural changes in zircon under a-decay irradiation. Phys Rev B 65:180102(R)

Trachenko K, Dove MT, Geisler T, Todorov I, Smith B (2004) Radiation damage effects and percolation theory. J Phys Condens Mat 16:S2623-S2627

Tringe JW, Felter TE, Talley CE, Morse JD, Stevens CG, Castelaz JM, Wetzel C (2007) Radiation damage mechanisms for luminescence in Eu-doped GaN. J Appl Phys 101:054902

Vance ER, Milledge HJ (1972) Natural and laboratory $\alpha$-particle irradiation of diamond. Mineral Mag 38:878-881

Vance ER, Harris JW, Milledge HJ (1973) Possible origins of $\alpha$-damage in diamonds from kimberlite and alluvial sources. Mineral Mag 39:349-360

Vaz JE, Senftle FE (1971) Thermoluminescence study of the natural radiation damage in zircon. J Geophys Res 76:2038-2050

Wang LM, Gong WL, Wang SX, Ewing RC (1999) Comparison of ion-beam irradiation effects in $\mathrm{X}_{2} \mathrm{YO}_{4}$ compounds. J Am Ceram Soc 82:3321-3329

Wasiliewski PJ, Senftle FE, Vaz JE, Thorpe AN, Alexander CC (1973) A study of the natural $\alpha$-recoil damage in zircon by infrared spectra. Radiat Eff Defect S 17:191-199

Weber WJ (1990) Radiation-induced defects and amorphization in zircon. J Mater Res 5:2687-2697

Weber WJ, Ewing RC, Wang LM (1994) The radiation-induced crystalline-to-amorphous transition in zircon. J Mater Res 9:688-698 
Weber WJ, Ewing RC, Catlow CRA, Dias de la Rubia T, Hobbs LW, Kinoshita C, Matzke H, Motta AT, Nastasi M, Salje EKH, Vance ER, Zinkle SJ (1998) Radiation effects in crystalline ceramics for the immobilization of high-level nuclear waste and plutonium. J Mater Res 13:1434-1484

Weikusat C, Miletich R, Glasmacher UA, Trautmann C, Neumann R (2010) Heavy-ion irradiation on crystallographically oriented cordierite and the conversion of molecular $\mathrm{CO}_{2}$ to $\mathrm{CO}$ : a Raman spectroscopic study. Phys Chem Miner 37:417-424

Xue LH, Gong WL (2000) A study on Raman and photoluminescence spectra of the aeschynite group minerals. Spectrosc Spect Anal 20:827-829 (in Chinese)

Zaitsev AM (2001) Optical properties of diamond. Springer, Berlin Heidelberg New York, 502 p. Ziegler JF (1999) Stopping of energetic light ions in elemental matter. J Appl Phys 85:1249-1272 Ziegler JF, Biersack JP, Littmark U (1985) The stopping and range of ions in solids. In: Ziegler JF (ed) The stopping and ranges of ions in matter, vol 1. Pergamon Press, New York

Ziegler JF, Biersack JP, Ziegler MD (2008) SRIM - The Stopping and Range of Ions in Matter. SRIM Co. (ISBN 0-9654207-1-X) 

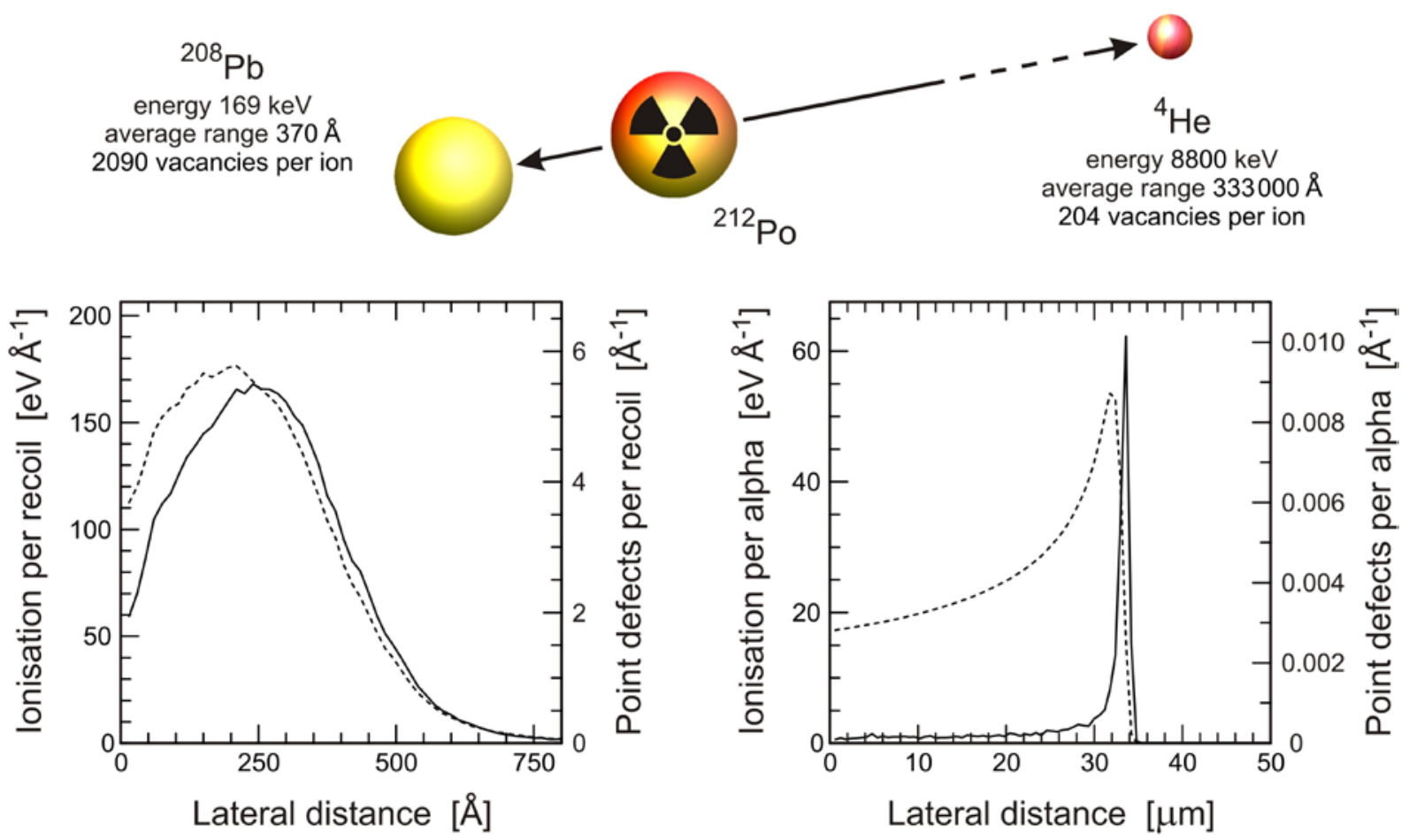

Fig. 1. Simplified sketch (not to scale) of an alpha-decay event in monazite-(Ce) $\left(\mathrm{CePO}_{4}\right)$, for the example of the ${ }^{212} \mathrm{Po} \rightarrow{ }^{208} \mathrm{~Pb}$ decay in the ${ }^{232} \mathrm{Th}$ chain, along with distribution patterns of the electronic (dashed graphs) and nuclear stopping (solid graphs) of the recoil nucleus (left) and the ejected alpha particle (right) as predicted by SRIM calculation. Note the different lateral scales; the travel distance of the alpha particle exceeds that of the recoiled daughter nucleus ca. 1000 times

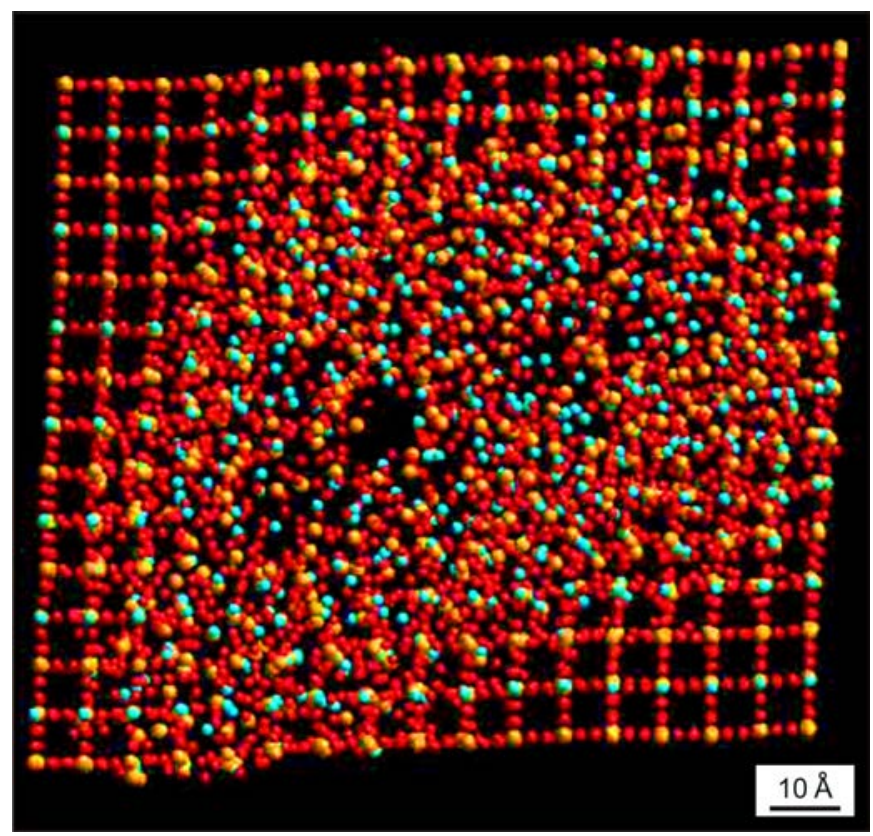

Fig. 2. Sketch (produced by MD simulation) of a damage cluster generated by a single recoil nucleus in zircon $\left(\mathrm{ZrSiO}_{4}\right)$. The recoil nucleus moved from the lower left to beyond the upper right corner of the pictured area. Image by permission of $\mathrm{K}$. Trachenko 

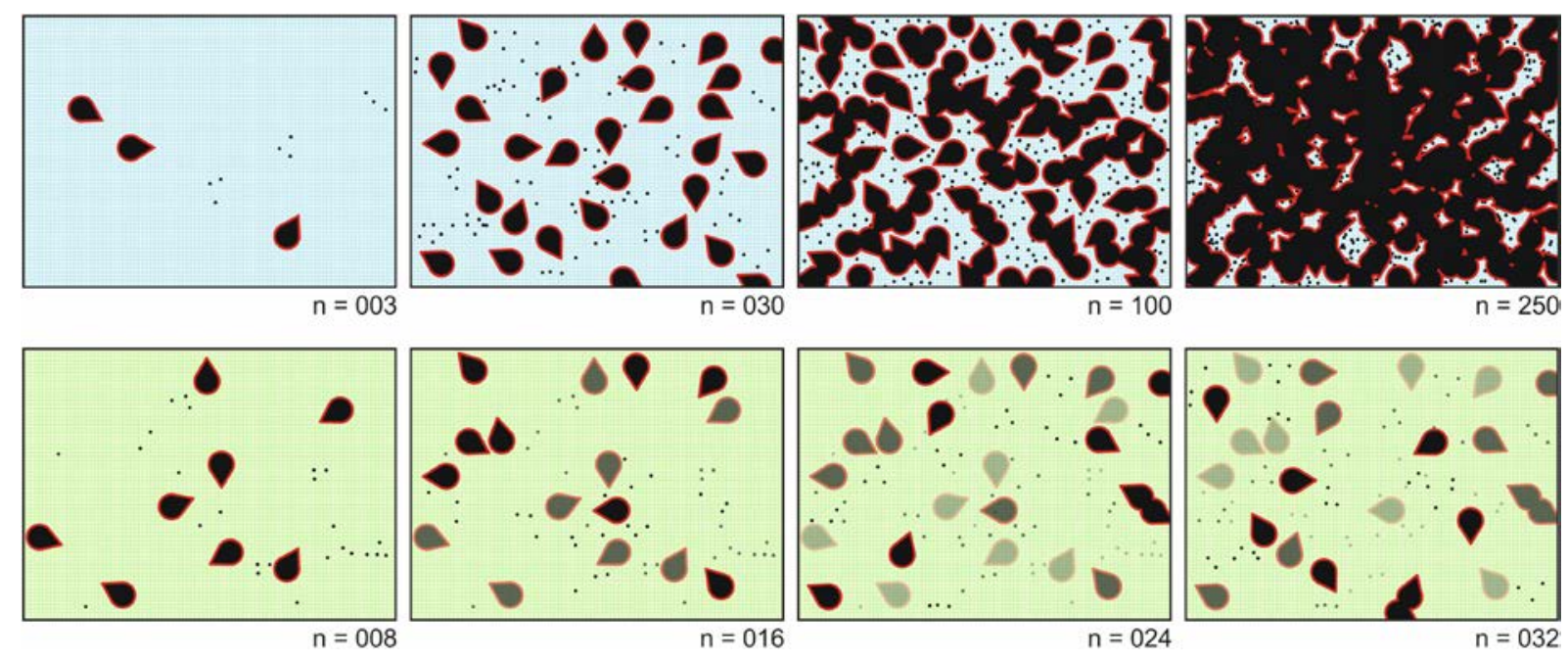

Fig. 3. Simplified visualisation of the metamictisation process. Recoil-damage clusters are shown as droplets-shaped areas, and scattered point defects generated by alpha particles are shown as small dots. The number (n) of events in the area shown is quoted. Upper row: Damage accumulation leads to a three-dimensional network through inter-connection of the recoil clusters $(n=100)$ and eventually to a predominantly amorphous solid with isolated crystalline "islands" $(n=250)$. This process may finally lead to an amorphous, metamict form (not shown). Lower row: Damage cannot be stored if the thermal annealing (visualised as fading of damage clusters and point defects) exceeds the accumulation rate 

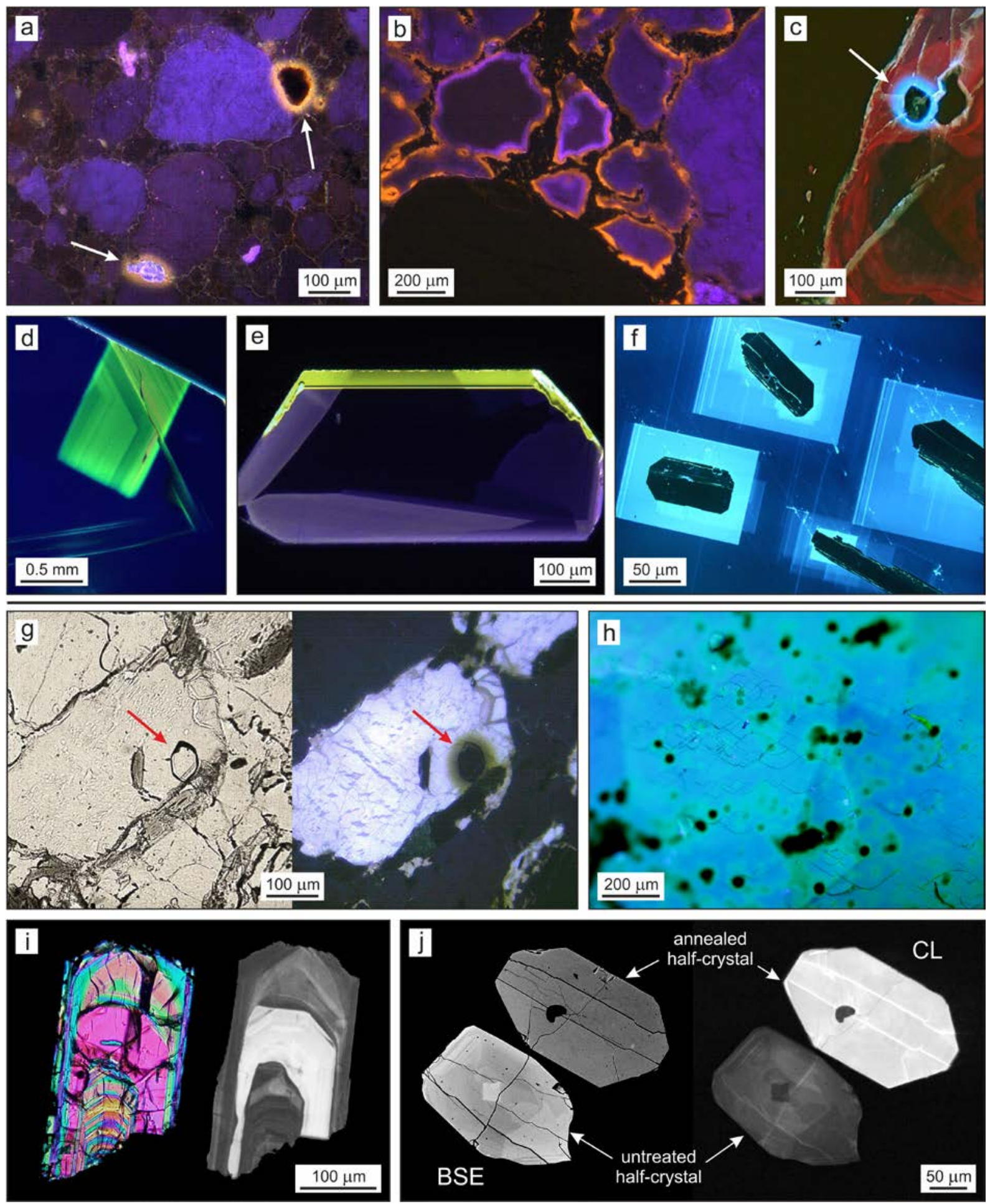

Fig. 4. Images of mineral samples whose luminescence emission is enhanced (a-f) or depleted (g-j), respectively, due to irradiation effects. a OM-CL photomicrograph of sandstone from the Espinaco formation, Minas Gerais, Brazil. Quartz shows orange defect-CL around two radioactive inclusions (arrows). Image courtesy J. Götze. b OM-CL photomicrograph of a quartz conglomerate from Witwatersrand, RSA. The orange defect-CL was generated from alpha particles emitted from Ubearing fluids. Image courtesy J. Götze. c OM-CL photomicrograph of a kyanite from the Dora Maira Massif. The kyanite shows blue defect-CL around a monazite inclusion (arrow). Image courtesy H.-P. Schertl. d PL image ( $<370 \mathrm{~nm}$ UV illumination) of a slice of a type IaA diamond after local irradiation with $22.5 \mathrm{MeV}^{12} \mathrm{C}$ ions (irradiation along the direction of view) and subsequent heating at $1000^{\circ} \mathrm{C}$. The irradiated spot shows intense yellowish-green defect luminescence. Sample courtesy 
J.W. Harris. e OM-CL photomicrograph of a synthetic zircon crystal irradiated with $8.8 \mathrm{MeV}^{4} \mathrm{He}$ ions (irradiation direction in the image plane; from the top). The volume area penetrated by the helium ions (thickness ca. $33 \mu \mathrm{m}$ ) shows yellow broad-band, defect emission. Sample courtesy J.M. Hanchar, image J. Götze. f PL photomicrograph of a thin section containing single crystals of synthetic, Gddoped monazite embedded in araldite epoxy. Scanning the sample with an electron beam during SEM imaging has caused luminescent defect areas. g Combination of plane-polarised light (left) and OMCL (right) photomicrographs of a K-feldspar containing a large monazite inclusion, from the Strangways Range, Australia. In the alpha halo surrounding the inclusion (arrows), the blue luminescence of the feldspar is decreased notably and shows a yellowish brown hue. Sample courtesy A. Möller, images J. Götze. h PL photomicrograph of the surface of a rough diamond from Namaqualand, RSA. In circular alpha haloes (having pale orange-brown radio-colouration), the blue luminescence of the diamond is virtually extinct. Sample courtesy J.W. Harris. i Combination of cross-polarised light (left) and SEM-CL photomicrographs of a heterogeneous zircon crystal from the Adirondack Mountains, New York State. The CL correlates inversely with the interference colours; the central low-actinide zone ( $3^{\text {rd }}$ order pink interference colour) yielded the highest CL intensity. Sample courtesy J.M. Hanchar, CL image A. Kronz. j Combination of BSE and SEM-CL image of a cut-in-half zircon grain from the Bluffpoint quartz diorite, Ontario. One of the two half-crystals was annealed at $1300{ }^{\circ} \mathrm{C}$ to remove the radiation damage, which has resulted in dramatic recovery of its CL emission. Sample courtesy D.W. Davis, images A. Kronz

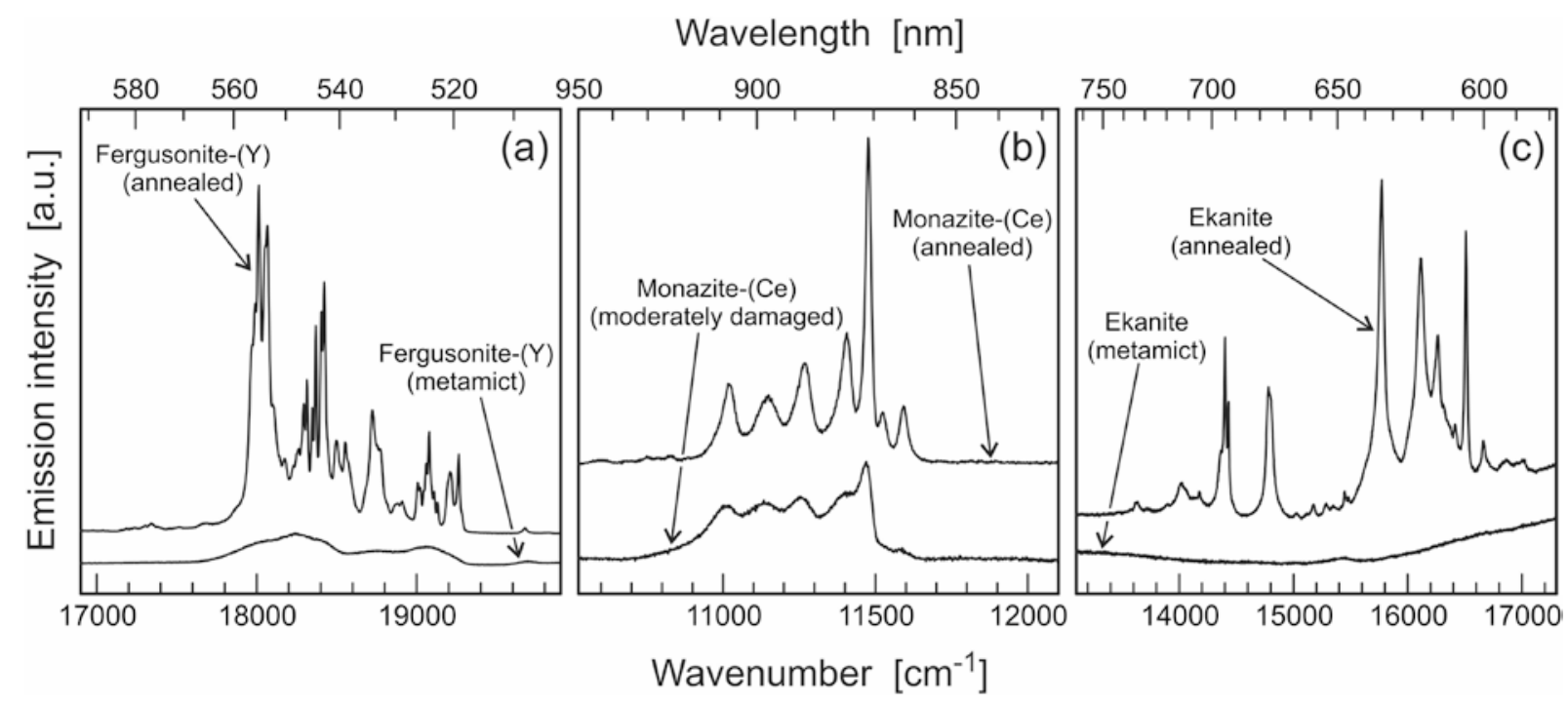

Fig. 5 Three examples for effects of radiation damage on REE-related emissions. a PL spectra of fergusonite-(Y) from Berere, Madagascar (mainly $\mathrm{Er}^{3+}$ and $\mathrm{Ho}^{3+}$ ). b Monazite-(Ce) from Moss, Norway (all emission lines related to $\mathrm{Nd}^{3+}$ ). c Ekanite from Ratnapura, Sri Lanka (affected mainly by $\mathrm{Pr}^{3+}$ and $\mathrm{Sm}^{3+}$ ). In all three cases, notable recovery of REE-related emissions is observed after structural reconstitution of the host minerals upon dry thermal annealing. Sample courtesy C. Schnier (fergusonite), A. Massanek (monazite), and I.V. Pekov (ekanite) 


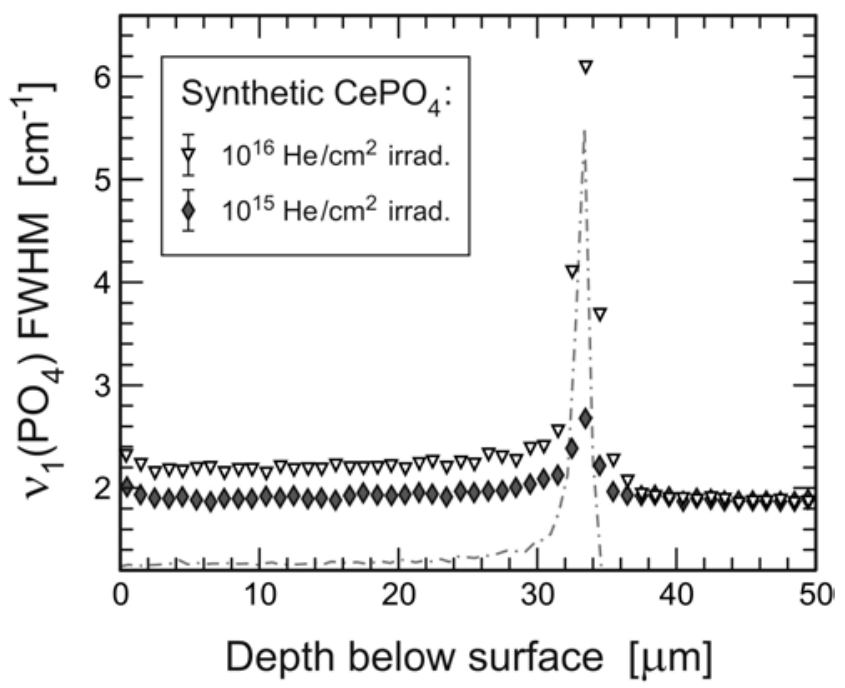

Fig. 6 Raman line-scans of He-irradiated samples: FWHM of the symmetric $\mathrm{PO}_{4}$ stretching band near (main $\mathrm{A}_{\mathrm{g}}$ mode of monoclinic $\mathrm{CePO}_{4}$ near $970 \mathrm{~cm}^{-1}$ ) plotted versus penetration depth. Band broadenings indicates increasing disturbance of the short-range order; their depth profiles correlate very well with the defect distribution predicted by SRIM calculation (grey dash-dot graph shown for comparison; cf. Fig. 1)

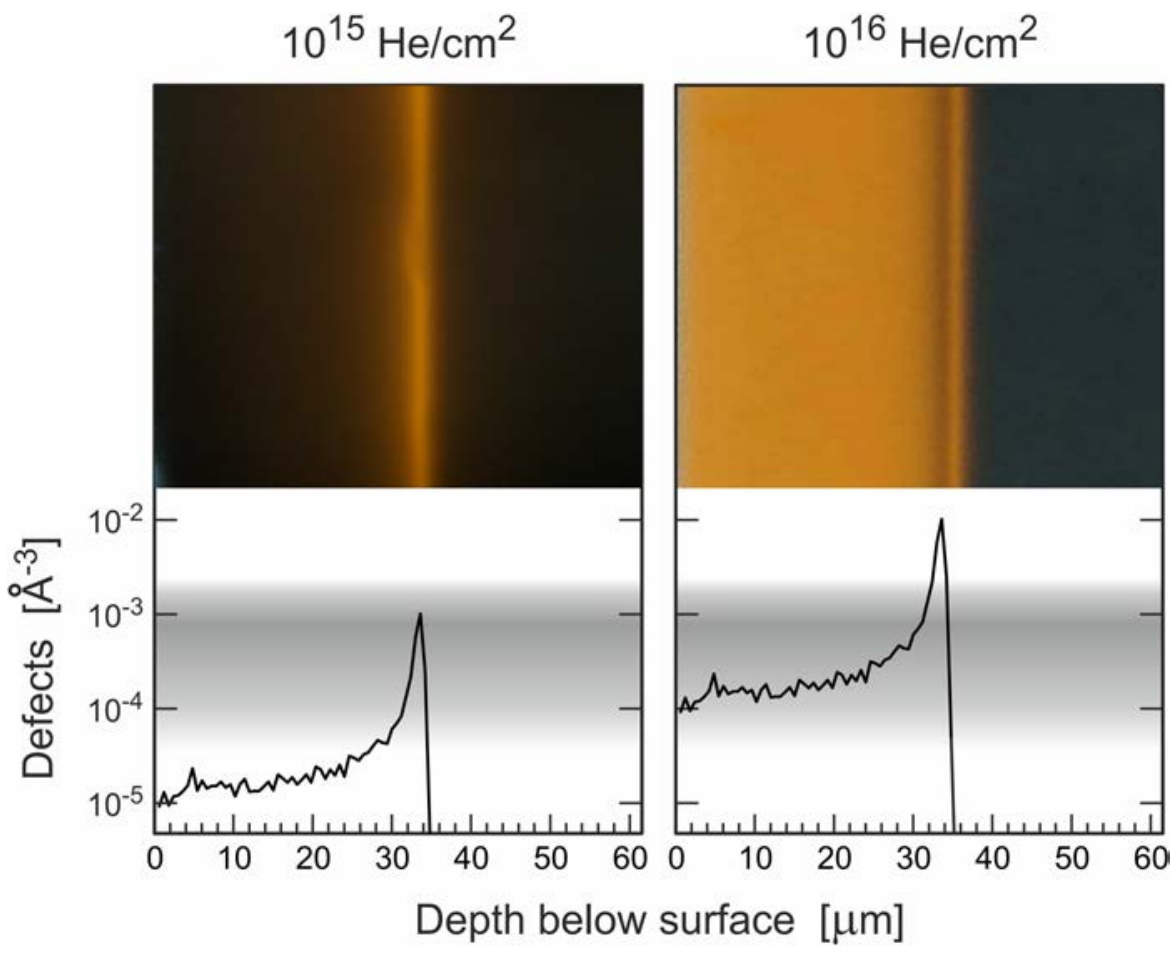

Fig. 7 Dependence of the orange defect-luminescence in monoclinic $\mathrm{CePO}_{4}$ on the irradiation fluence (8.8 MeV He irradiations). PL images ( $<370 \mathrm{~nm}$ excitation) are compared with defect distributions predicted by SRIM calculation. The defect-PL is observed only in a relatively narrow range of defect densities (visualised as gray bar) 

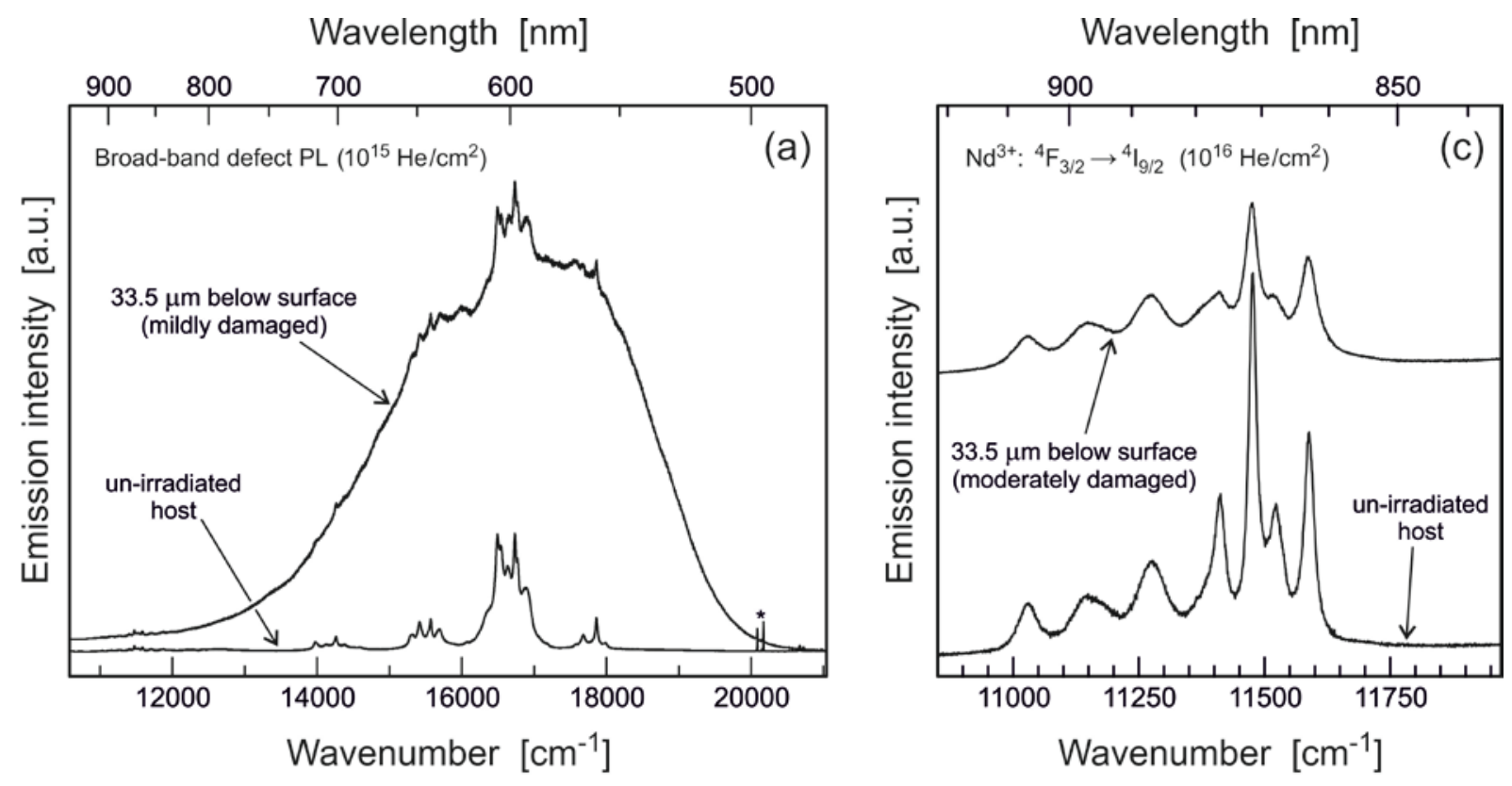

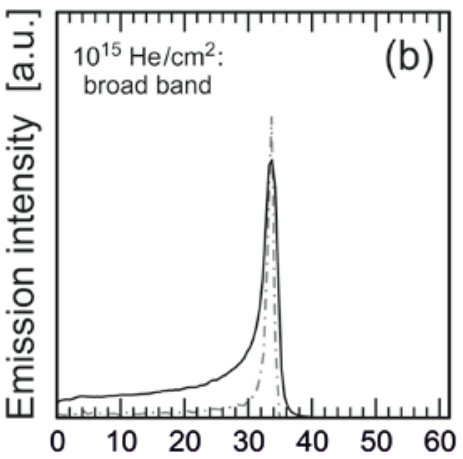

Depth bel. surface $[\mu \mathrm{m}]$

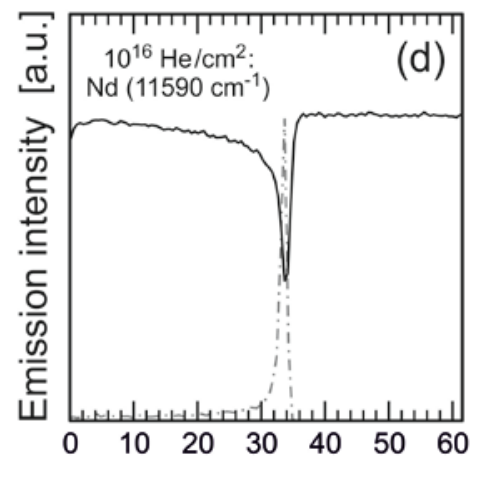

Depth bel. surface $[\mu \mathrm{m}]$

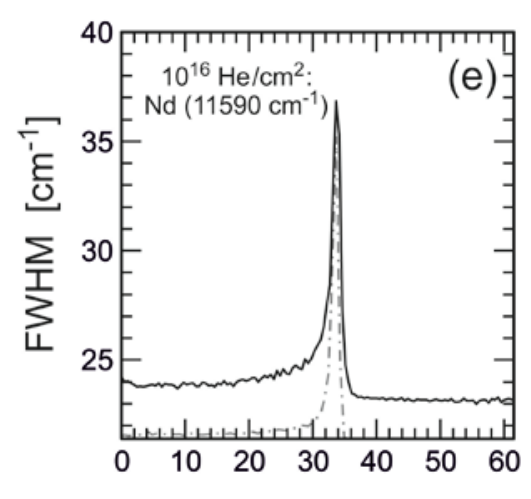

Depth bel. surface $[\mu \mathrm{m}]$

Fig. 8 Photoluminescence emission of a synthetic $\mathrm{CePO}_{4}$ crystal irradiated with $8.8 \mathrm{MeV}$ He ions $\left(10^{15}\right.$ and $10^{16}$ ions per $\left.\mathrm{cm}^{2}\right)$. a PL spectrum (488 nm excitation) of the of the spot irradiated with $10^{15}$ $\mathrm{He} / \mathrm{cm}^{2}$, obtained in the most damaged volume area (i.e., the stripe near ca. $33.5 \mu \mathrm{m}$ below the surface); compared to the spectrum of the un-damaged host. Radiation damage results in the creation of an orange, broad-band defect emission whereas narrow emission bands of trace-REEs (mainly $\mathrm{Sm}^{3+}$ ) start to became less defined and lose some intensity. Low-intensity Raman bands are marked with an asterisk. b Plot of the integral intensity of the orange defect-emission against depth (spot irradiated with $10^{15} \mathrm{He} / \mathrm{cm}^{2}$ ). The emission intensity correlates well with the defect concentration predicted by SRIM calculation (grey dash-dot graph). c PL spectrum (633 nm excitation) of the most damaged region of the spot irradiated with $10^{16} \mathrm{He} / \mathrm{cm}^{2}$, in comparison with the un-damaged host, showing the damage-induced broadening of a $\mathrm{Nd}^{3+}$ emission in the NIR range. d,e Plots of intensity and FWHM of the $11590 \mathrm{~cm}^{-1}$ (863 nm wavelength) Stark sub-level of the ${ }^{4} \mathrm{~F}_{3 / 2} \rightarrow{ }^{4} \mathrm{I}_{9 / 2} \mathrm{Nd}^{3+}$ emission against depth (spot irradiated with $10^{16} \mathrm{He} / \mathrm{cm}^{2}$ ). Line broadening and intensity loss correlate again with the defect distribution (SRIM; grey dash-dot graph) 